\title{
Effect of heparan sulfate and gold nanoparticles on muscle development during embryogenesis
}

This article was published in the following Dove Press journal:

International Journal of Nanomedicine

5 December 201 I

Number of times this article has been viewed

\author{
Marlena Zielinska ${ }^{1,2}$ \\ Ewa Sawosz' \\ Marta Grodzik' \\ Mateusz Wierzbicki' \\ Maria Gromadka' \\ Anna Hotowy 3 \\ Filip Sawosz ${ }^{3}$ \\ Andrzej Lozicki' \\ Andrè Chwalibog ${ }^{3}$ \\ 'Division of Biotechnology and \\ Biochemistry of Nutrition, Warsaw \\ University of Life Sciences, Warsaw, \\ ${ }^{2}$ The Kielanowski Institute of Animal \\ Physiology and Nutrition, \\ Jablonna, Poland; ${ }^{3}$ Department \\ of Basic Animal and Veterinary \\ Sciences, University of Copenhagen, \\ Frederiksberg, Denmark
}

Correspondence: André Chwalibog University of Copenhagen, Department of Basic Animal and Veterinary Sciences, Groennegaardsvej 3, 1870 Frederiksberg, Denmark

Tel +453533 3044

Fax +453533 3020

Email ac@life.ku.dk
Purpose: It was hypothesized that heparan sulfate (HS) as an essential compound for myogenesis and nanoparticles of gold (nano-Au) as highly reactive compounds can affect muscle development as a consequence of molecular regulation of muscle cell formation, and that these effects may be enhanced by a complex of HS conjugated with nano-Au. The objective of the present study was to determine the effect of administration of nano-Au, HS, and a nano-Au+HS complex on the morphological and molecular characteristics of breast muscle during embryogenesis.

Methods: Chicken embryos were used as in vivo model. Fertilized chicken eggs $(n=350)$ were randomly divided into the control group and the groups treated with nano-Au, HS, and nano-Au+HS. The experimental solutions were given in ovo on the first day of incubation and the embryos were evaluated on day 20 of incubation. The methods included biochemical indices in blood, immunohistochemistry, microscopy (transmission electron microscopy, scanning electron microscopy, confocal), and gene expression at the messenger ribonucleic acid and protein levels.

Results: The treatments did not adversely affect mortality, organ weight, and homeostasis of the embryos. HS stimulated the development and maturation of breast muscle by increasing the number of nuclei, satellite cells, and muscle fibers and affected the expression of basic fibroblast growth factor- 2 and paired-box transcription factor-7. Furthermore, the nano-Au+HS complex contributed to the increased number of myocytes and nuclei in chicken embryo muscles.

Conclusion: The results indicate that the administration of HS and nano-Au affects muscle development and that this effect is enhanced by conjugating HS with nano-Au.

Keywords: gold nanoparticles, heparan sulfate, muscle development, embryogenesis, chicken

\section{Introduction}

Myogenesis is the key process of muscle development occurring during embryogenesis, with the final number of muscle cells nearly established just before birth. Myogenesis begins with the conversion of pluripotent cells into myoblast precursors, which, depending on extracellular signals, undergo migration or proliferation. Afterwards, the precursors stop dividing and some form uninuclear totipotential cells, ie, satellite cells, while the remaining myoblasts begin to differentiate. Subsequently, they undergo fusion to form multinucleated myotubes, which become muscle cells. The process of formation of muscle is almost completed at the time of hatching, and the numbers of muscle fibers and nuclei in muscle cells are almost fixed. ${ }^{1,2}$ Satellite cells are potentially mitotically active myogenic cells, located at the periphery of muscle fibers, between the sarcolemma and the basement membrane of developed muscle fibers. In contrast to muscle cells, satellite cells retain the capacity for DNA replication and mitotic division, and have 
the ability to proliferate in response to muscle damage, hence they support the process of muscle regeneration in postnatal life. ${ }^{3}$ In the muscles of birds, satellite cells appear between day 13 and day 16 of embryogenesis. ${ }^{4}$

The factor responsible for renewing the pool of satellite cells is the protein paired-box transcription factor-7 (Pax-7). ${ }^{1}$ It affects the transcriptional activation of genes and regulates the development of myogenic cells. ${ }^{5}$ In Pax-7-deficient neonatal mice, a lack of satellite cells in crossstriated skeletal muscles was observed, suggesting that this is a key factor responsible for the formation of satellite cells, ${ }^{6}$ and is therefore an excellent marker of satellite cell development. ${ }^{7}$

During embryogenesis, the activity of myoblasts and satellite cells is highly affected by the extracellular matrix, consisting of an organized network of proteins and polysaccharides (collagen, proteoglycans, and glycoproteins). ${ }^{2}$ Proteoglycans play an important role in the differentiation of muscle, regulating the reactivity of myoblasts and satellite cells by acting on basic fibroblast growth factor-2 $(F G F-2)$ and the family of transforming growth factors. ${ }^{8}$ The interaction between muscle cells and $F G F$-2 depends on several factors, including the presence of heparan sulfate (HS) in the extracellular matrix. HS mediates interactions with a variety of extracellular ligands and participates in the proliferation, differentiation, migration, and adhesion of cells. ${ }^{9}$ The genetic capacity for proper development of muscle tissue in embryos of animals and humans may be hampered by a shortage of sulfur signaling compounds in the extracellular matrix, especially glycosaminoglycans. ${ }^{10}$

The unique properties of gold nanoparticles (nano-Au) are due to their small size, much larger surface area per unit mass compared with larger particles, and a greater proportion of atoms exposed on the surface of the particles, making them much more reactive than larger particles. ${ }^{11}$ Nano-Au exhibit a strong affinity for thiol groups, which allows efficient and selective bonding with intracellular compounds. ${ }^{12} \mathrm{Nano}-\mathrm{Au}$ can penetrate cells by endocytosis, and they can be carriers of pharmaceuticals, nucleic acids, and other biologically active substances. ${ }^{13,14}$ The application of drugs conjugated with nano-Au has shown high precision in the delivery of drugs, and significantly decreased their doses. ${ }^{15}$

It has been demonstrated that low concentrations of nano-Au are not toxic to human cells, ${ }^{16}$ but cause toxicity in zebrafish ${ }^{17}$ and when using higher doses deposited in animal tissues. ${ }^{18}$ The present experiment was not designed to evaluate potential toxicity of nano-Au but to measure their effects on muscle development when used in a small concentration ( $50 \mathrm{mg} / \mathrm{L}$ solution).

Nano-Au can create biocomplexes with organic compounds in the process of self-assembly (self-organization) using noncovalent bonds. ${ }^{19,20}$ The phenomenon of selforganization allows the creation of new structures in a simple and natural way, and in this respect, nano-Au seem to be a promising candidate for self-assembly processing of biomolecules like HS.

It was hypothesized that HS as an essential compound for myogenesis and nano-Au as highly reactive compounds can affect muscle development as a consequence of molecular regulation of muscle cell formation, and that these effects may be enhanced by a complex of HS conjugated with nano-Au. The objective of the present study was to determine the effect of administration of HS, nano-Au, and the nano-Au+HS complex on the morphological and molecular characteristics of muscle development, particularly on the number of muscle and satellite cells.

\section{Materials and methods Solutions}

The hydrocolloid of nano-Au $(50 \mathrm{mg} / \mathrm{L})$ obtained from Nano-Tech (Warsaw, Poland) was produced by an electric nonexplosive patented method (Polish patent 3883399) from high purity metals (99.99\%) and high purity demineralized water. The structure of the nanoparticles was visualized by a JEM-1220 transmission electron microscope (TEM) (JEOL, Tokyo, Japan) and the diameter ranged from 5-70 nm (Figure 1). HS was provided by Iduron Ltd (Manchester, United Kingdom) as a K5 polysaccharide derivative. Produced in Escherichia coli K5, it has a repeat unit structure identical to the nonsulfated regions of HS. The highly sulfated derivative was applied where sulfation was carried out by chemical and enzymatic methods. This polymer was $\mathrm{N}$-sulfated, O-sulfated at C-6 of $\alpha$-N-sulfo-D-glucosamine, $\mathrm{C} 2$ and $\mathrm{C} 3$ of glucuronic acid, and had variable O-sulfation at $\mathrm{C} 3$ of $\alpha-\mathrm{N}$-sulfo-D-glucosamine.

HS was conjugated with nano-Au by mixing the HS water solution $(0.032 \mathrm{mg} / \mathrm{L})$ with nano-Au hydrocolloid (50 mg/L) in an ultrasonic bath (Sonorex Super RK 514 H; Bandelin Electronic, Berlin, Germany) for 30 minutes at $36^{\circ} \mathrm{C}$ at a frequency of $50 / 60 \mathrm{~Hz}$.

\section{Experiment}

Fertilized chicken eggs $(n=350)$ were randomly divided into four treatment groups: (1) control group (without injection), (2) nano-Au group (with nano-Au solution), (3) HS group (with HS solution), and (4) nano-Au+HS group (with mixture of nano-Au and HS). The experimental solutions were given in ovo on the first day of incubation by injecting $500 \mu \mathrm{L}$ of each solution into the air sack. 


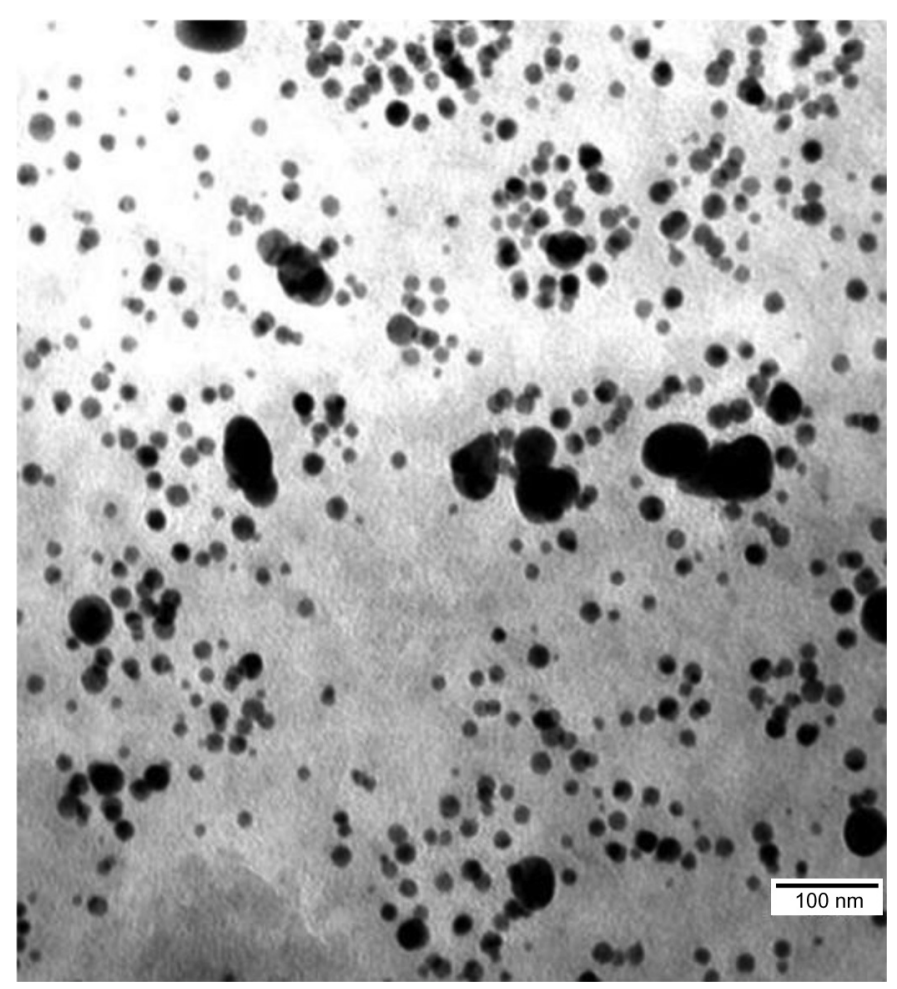

Figure I Image of hydrocolloid of gold nanoparticles visualized using transmission electron microscopy.

The embryos were evaluated on day 20 of incubation. The embryos were weighed together with the yolk sack, decapitated, and blood samples from the carotid artery were withdrawn and collected in Eppendorf polymerase chain reaction (PCR) tubes (Eppendorf AG, Hamburg, Germany). Samples were incubated at room temperature until clotting and then centrifuged for 10 minutes $(14,500 \times \mathrm{g})$. The resulting blood serum samples were stored at $-30^{\circ} \mathrm{C}$ until further analysis. The liver, heart, and spleen were collected and weighed. Samples of the breast muscles $(4 \times 6 \times 2 \mathrm{~mm})$ were collected in liquid nitrogen for immunohistochemistry, enzyme-linked immunosorbent assay, and confocal microscopy preparations or fixed in glutaraldehyde for electron microscopy preparation or collected in RNAlater ${ }^{\circledR}$ ribonucleic acid (RNA) Stabilization Solution (Applied Biosystems/Ambion, Austin, TX) for gene expression analysis.

The experimental procedures were approved by, and complied with the guidelines of, the National Ethical Committee of Animal Experimentation, Poland.

\section{Analytical methods}

\section{Evaluation of embryo development}

Embryo development was evaluated on day 20 of embryogenesis. The morphological structure was compared with the standard described by Hamburger and Hamiliton. ${ }^{21}$
Concentrations of magnesium, calcium, phosphorus, triglycerides, cholesterol in very-low-density lipoprotein, glucose, and the activities of aspartate aminotransferase, alanine aminotransferase, alkaline phosphatase, and lactate dehydrogenase in blood serum were measured by dry chemistry methods using the chemical analyzer Johnson and Johnson Vitros ${ }^{\circledR}$ DT60 II (Ortho-Clinical Diagnostics Inc, Raritan, NJ).

\section{Immunohistochemistry}

Frozen $\left(-80^{\circ} \mathrm{C}\right)$ breast muscles were cut on a cryostat (Leica CM1900; Leica Microsystems GmbH, Wetzlar, Germany) into $7 \mu \mathrm{m}$ thick sections and put on microscopic slides covered with poly-L-lysine (Waldemaar Knittel Gläsbearbeitungs, Braunschweig, Germany). Fixation was performed in 4\% paraformaldehyde for 30 minutes and then in $0.5 \%$ Tween $^{\circledR} 20$ (Bio-Rad Laboratories, Hercules, CA) for 5 minutes. Fixed slides were kept at $-20^{\circ} \mathrm{C}$ until further processing.

Specimens were hydrated with 10 minutes incubation in phosphate buffered saline (PBS; Sigma-Aldrich Corporation, St Louis, MO) at room temperature. Staining was performed in the dark, using a solution containing $1 \mu \mathrm{g} / \mathrm{mL}$ 4',6-diamidino-2-phenylindole (DAPI; Sigma-Aldrich) in PBS. The incubation lasted for 20 minutes and was followed 
by a triple rinse of the slides with PBS. The specimens were then coverslipped using ProLong ${ }^{\circledR}$ Gold Antifade Reagent (Life Technologies, Carlsbad, CA).

Fixed preparations were hydrated for 10 minutes in PBS at room temperature. Specimens were then incubated in a solution containing 2\% goat serum (Sigma-Aldrich) and $1 \%$ bovine serum albumin (Sigma-Aldrich) for 20 minutes at room temperature to block nonspecific binding. In the next step, the specimens were incubated with the primary antibody (Pax-7; Santa Cruz Biotechnology, Inc, Santa Cruz, CA) diluted 1:200 for 60 minutes at room temperature. Subsequently, excess antibodies were washed off with three rinses of PBS and the secondary antibody (antimouse immunoglobulin G-fluorescein isothiocyanate antibody produced in goat; Sigma-Aldrich) diluted 1:1000 was applied. After a triple rinse of the slides in PBS, DAPI staining was performed.

\section{Microscopy}

Immunohistochemically stained specimens were visualized using a FluoView FV-1000 confocal microscope equipped with FV10-ASW version 1.4. software (Olympus Corporation, Warsaw, Poland). The pictures were analyzed using the cellSens ${ }^{\circledR}$ Dimension program (Olympus).

The breast muscles were examined using a Quanta $^{\mathrm{TM}}$ 200 scanning electron microscope (SEM; FEI Company, Hillsboro, OR), using environmental SEM operating mode and by TEM. For observations with SEM, samples were stored at $-30^{\circ} \mathrm{C}$. Frozen $\left(-30^{\circ} \mathrm{C}\right)$ samples were cleanly cut with a scalpel into $1 \mathrm{~mm}$ thick sections on frozen pieces of wax. While still frozen, a sample section was placed on a Peltier table within a standard cooled microscope column (at $-5^{\circ} \mathrm{C}$ for blood vessels and $-10^{\circ} \mathrm{C}$ for cartilage) in the sample chamber under high vacuum $\left(10^{-5}\right.$ Torr). For observations with TEM, immediately after dissection, tissues were cut into pieces of about $1 \mathrm{~mm}^{3}$ and fixed in a $2.5 \%$ glutaraldehyde solution (Sigma-Aldrich) in 0.1 M phosphate buffer (pH 6.9). Samples were then rinsed in the same buffer and transferred to a $1 \%$ osmium tetroxide solution (Sigma-Aldrich) in $0.1 \mathrm{M}$ phosphate buffer ( $\mathrm{pH}$ 6.9) for 1 hour. Subsequently, the samples were rinsed in distilled water, dehydrated in an ethanol gradient, and impregnated with epoxy embedding resin (Fluka Epoxy Embedding Medium Kit; Sigma-Aldrich). The next day, samples were embedded in the same resin and baked for 24 hours at $36^{\circ} \mathrm{C}$. The blocks were then transferred to a $60^{\circ} \mathrm{C}$ incubator and baked for another 24 hours. The blocks were cut into ultrathin sections $(50-80 \mathrm{~nm})$ using an ultramicrotome (Ultratome III; LKB Products, Bromma,
Sweden) and transferred onto copper grids, 200 mesh (Agar Scientific Ltd, Stansted, Essex, United Kingdom). Subsequently, the sections were contrasted using uranyl acetate dihydrate (Sigma Aldrich) and lead citrate (lead (II) citrate tribasic trihydrate; Sigma-Aldrich).

\section{Gene expression of Pax-7 and FGF-2 at messenger RNA (mRNA) level}

The tissue dissected from the breast muscle was homogenized in TRIzol ${ }^{\circledR}$ Reagent (Life Technologies), and total RNA was extracted according to the manufacturer's instructions. The RNA samples were purified, using the SV Total RNA Isolation System (Promega Corporation, Madison, WI) and quantified using a NanoDrop ND 1000 spectrophotometer (Thermo Fisher Scientific, Waltham, MA). Using reverse transcriptase with oligo(dT) (Promega) and random primers (TAG Copenhagen A/S, Copenhagen, Denmark), 2 mg of total RNA was reverse transcribed, after which real-time PCR was performed with complementary DNA and genespecific primer pairs (TAG Copenhagen; Table 1) mixed with LightCycler ${ }^{\circledR} 480$ SYBR Green I Master mix (Roche Applied Science, Penzberg, Germany) in a LightCycler ${ }^{\mathbb{8}} 480$ RealTime PCR system (Roche Applied Science). The samples were first denatured for 5 minutes at $95^{\circ} \mathrm{C}$ and then amplified using 45 cycles of 10 seconds at $95^{\circ} \mathrm{C}$ (denaturation), 10 seconds at $60^{\circ} \mathrm{C}-62^{\circ} \mathrm{C}$ (annealing), and 9 seconds at $72^{\circ} \mathrm{C}$ (elongation), followed by quantification. A melting curve program $\left(56^{\circ} \mathrm{C}-97^{\circ} \mathrm{C}\right.$ with a heating rate of $0.11^{\circ} \mathrm{C} /$ second and five acquisitions per $1^{\circ} \mathrm{C}$ ) was applied to verify the specificity of the product. For each complementary DNA, the reaction was performed in triplicate. For analyses, relative quantification was applied with $A C T B$ and EEF1- $\alpha$ used as the housekeeping genes.

\section{Gene expression of FGF-2 at protein level}

Frozen breast muscle tissue samples were homogenized on ice using RIPA lysis and extraction buffer (Thermo

Table I Oligonucleotide sequences used in polymerase chain reaction

\begin{tabular}{|c|c|c|}
\hline Gene & Size & Primer sequences $\left(5^{\prime}\right.$ to $\left.3^{\prime}\right)$ \\
\hline \multirow[t]{2}{*}{$\overline{A C T B}$} & ca. 169 bp & Forward: GTC CAC CTT CCA GCA GAT GT \\
\hline & & Reverse: ATA AAG CCA TGC CAA TCT CG \\
\hline \multirow[t]{2}{*}{$E E F I-\alpha$} & ca. 85 bp & Forward: AGC AGA CTT TGT GAC CTT GCC \\
\hline & & Reverse: TGA CAT GAG ACA GAC GGT TGC \\
\hline \multirow[t]{2}{*}{ FGF-2 } & ca. 151 bp & Forward: GGC ACT GAA ATG TGC AAC AG \\
\hline & & Reverse: TCC AGG TCC AGT TTT TGG TC \\
\hline \multirow[t]{2}{*}{ PAX-7 } & ca. $135 \mathrm{bp}$ & Forward: CCA GTA GAG ACA GGC CAA GC \\
\hline & & Reverse: GGA GTT GGG AAG GAG TAG GG \\
\hline
\end{tabular}


Fisher Scientific) and a Polytron ${ }^{\circledR}$ PT 2100 homogenizer (Kinematica AG, Lucerne, Switzerland). Homogenates were left on ice for 30 minutes and were subsequently centrifuged for 20 minutes $\left(4^{\circ} \mathrm{C}, 12,500 \mathrm{rpm}\right)$. The supernatant was collected in chilled Eppendorf PCR tubes (Eppendorf AG). Supernatant samples were divided into two equal portions. One was used to evaluate the total protein concentration (Total Protein Kit, Micro Lowry, Peterson's Modification; Sigma-Aldrich). The second portion was used to perform the enzyme-linked immunosorbent test, using an Enzymelinked Immunosorbent Assay Kit for Gallinaceous FGF-2 (USCN Life Science, Tokyo, Japan). Reagents and plates were prepared accordingly to the manufacturer's standard procedure and incubated for 25 minutes under standard conditions. The degree of absorption was measured in a microplate reader Infinite ${ }^{\circledR}$ M200 PRO (Tecan Deutschland GmbH, Crailsheim, Germany).

\section{Statistical analysis}

Statistical analysis of data was carried out using a two-way analysis of variance test (Statgraphics Plus version 4.1; StatPoint Technologies, Inc, Warrenton, VA). The model included two factors (nano-Au and HS treatments) and interactions between the factors. Significant effects were stated when $P<0.05$.

\section{Results}

In the present experiment, embryos treated with HS had lower mortality than other groups. Nano-Au, HS, and nano-Au+HS complex did not affect embryo weight or the weight of organs, except for the heart being slightly smaller with HS treatment (Table 2). Furthermore, there was no significant effect on the measured biochemical indices in blood (Table 3 ).

To examine the influence of nano-Au and HS on muscle development, the number of nuclei was determined (DAPI staining) in the breast muscle, showing increased number of nuclei in treated embryos (Figure 2). The counted number of nuclei was significantly higher in embryos treated with nano-Au and nano-Au+HS than in the control group, and there was highly significant interaction between nano-Au and HS treatments (Table 4).

Breast muscle tissue was visualized by SEM, using the environmental SEM operating mode which allows observation with minimal distortion to the muscle structure. There were visual changes in the structure of the breast muscle in the groups treated with injections compared to the embryos from the control group (Figure 3). In the control group, the muscle fibers formed the most compact structure and the surface of individual muscle fascicles was smaller compared to the treatment groups. Furthermore, the distances between fascicles were greater and the area of fascicles was longer with sharper structures in the control group than in the treatment groups. Empty areas, which were seen around fascicles in the control group, were much smaller than in the treatment groups. In embryos treated with nano-Au, HS, and nano$\mathrm{Au}+\mathrm{HS}$, muscle fibers were organized in more rounded and well-developed fascicles, located equally within muscle. In the HS-treated groups, the connective tissue seen between muscle fascicles was better developed than in the other embryos. The structure of the muscle cross-section in the nano-Au+HS group was the most homogeneous and mature. Fascicles were the most rounded and filled with myofibers. The space around them also showed better connective tissue structure.

The evaluation of the morphology of breast muscles was carried out using TEM. While analyzing transverse section images of muscle samples from the control group, an enlargement area was seen between cells and cells were more rounded and less angular with a slightly stippled cytoplasm. Within cells, cylindrical myofibrils were seen; however, in the control group they were loosely spaced with larger spaces between myofibers than in the treatment groups. Also, myomere decay, unification of actin and

Table 2 Mortality and average weight of embryos and organs without (-) or with gold nanoparticles and heparan sulfate

\begin{tabular}{|c|c|c|c|c|c|c|c|c|c|}
\hline & \multicolumn{4}{|c|}{ Treatment } & \multicolumn{5}{|c|}{ ANOVA } \\
\hline & \multicolumn{2}{|c|}{ Without HS } & \multicolumn{2}{|c|}{ With HS } & \multicolumn{4}{|c|}{ Effect } & \multirow{3}{*}{$\frac{\text { Interaction }}{P}$} \\
\hline & \multirow[t]{2}{*}{-} & \multirow[t]{2}{*}{$\overline{\text { Nano-Au }}$} & \multirow[t]{2}{*}{-} & \multirow[t]{2}{*}{ Nano-Au } & \multicolumn{2}{|c|}{ Nano-Au } & \multicolumn{2}{|l|}{ HS } & \\
\hline & & & & & $P$ & SEM & $P$ & SEM & \\
\hline Mortality, \% & 13.6 & 15.6 & 9.52 & 8.33 & & & & & \\
\hline Embryo, \% e.w & 85.1 & 84.9 & 85.0 & 85.0 & 0.615 & 0.29 & 0.917 & 0.26 & 0.045 \\
\hline Liver, \% b.w & 1.66 & 1.75 & 1.72 & 1.69 & 0.074 & 0.030 & 0.447 & 0.029 & 0.613 \\
\hline Heart, \% b.w & 0.60 & 0.59 & 0.63 & 0.56 & 0.347 & 0.011 & 0.002 & 0.013 & 0.099 \\
\hline Spleen, \% b.w & 0.05 & 0.04 & 0.05 & 0.04 & 0.066 & 0.002 & 0.094 & 0.002 & 0.844 \\
\hline
\end{tabular}

Abbreviations: \% e.w, \% of egg weight; \% b.w, \% of body weight; ANOVA, analysis of variance; HS, heparan sulfate; nano-Au, gold nanoparticles; SEM, standard error of the mean. 
Table 3 Biochemical indices in the blood serum of chicken embryos without (-) or with gold nanoparticles and heparan sulfate

\begin{tabular}{|c|c|c|c|c|c|c|c|c|c|}
\hline & \multicolumn{4}{|c|}{ Treatment } & \multicolumn{5}{|c|}{ ANOVA } \\
\hline & \multicolumn{2}{|c|}{ Without HS } & \multicolumn{2}{|c|}{ With HS } & \multicolumn{4}{|l|}{ Effect } & \multirow{3}{*}{$\frac{\text { Interaction }}{P}$} \\
\hline & \multirow[t]{2}{*}{-} & \multirow[t]{2}{*}{$\overline{\text { Nano-Au }}$} & \multirow[t]{2}{*}{-} & \multirow[t]{2}{*}{ Nano-Au } & \multicolumn{2}{|c|}{ Nano-Au } & \multicolumn{2}{|l|}{ HS } & \\
\hline & & & & & $P$ & SEM & $P$ & SEM & \\
\hline Magnesium (mmol/L) & 0.75 & 0.88 & 0.75 & 0.88 & 0.702 & 0.516 & 0.477 & 0.129 & 0.882 \\
\hline Calcium (mmol/L) & 2.70 & 2.71 & 2.45 & 2.96 & 0.980 & 0.136 & 0.092 & 0.038 & 0.752 \\
\hline Phosphorus (mmol/L) & 1.73 & 1.69 & 1.71 & 1.70 & 0.651 & 0.060 & 0.916 & 0.059 & 0.751 \\
\hline Triglycerides (mmol/L) & 0.78 & 0.75 & 0.79 & 0.73 & 0.714 & 0.062 & 0.529 & 0.062 & 0.962 \\
\hline Cholesterol-VLDL (mmol/L) & 0.35 & 0.35 & 0.36 & 0.34 & 0.904 & 0.039 & 0.740 & 0.036 & 0.928 \\
\hline Glucose (mmol/L) & 10.6 & 10.2 & 10.1 & 10.2 & 0.502 & 0.51 & 0.689 & 0.507 & 0.899 \\
\hline Alkaline phosphatase (U/L) & 658 & 636 & 567 & 727 & 0.812 & 64.2 & 0.093 & 54.2 & 0.620 \\
\hline Aspartate aminotransferase (U/L) & 144 & 162 & 181 & 125 & 0.512 & 19.2 & 0.050 & 29.2 & 0.138 \\
\hline Alanine aminotransferase (U/L) & II.7 & 10.2 & 13.2 & 8.70 & 0.527 & $\mathrm{I} .707$ & 0.075 & 1.88 & 0.839 \\
\hline Lactate dehydrogenase (U/L) & 2720 & 3047 & 2945 & 2822 & 0.223 & 184.2 & 0.643 & 192.3 & 0.399 \\
\hline
\end{tabular}

Abbreviations: ANOVA, analysis of variance; HS, heparan sulfate; nano-Au, gold nanoparticles; SEM, standard error of the mean; VLDL, very-low-density lipoprotein.

myosin filaments, loose connective tissue, and occasional myelin structures were observed (Figure 4). Muscles from the nano-Au group were characterized by contracted cells and bigger myocytes. In the muscles from the HS group, a higher number of satellite muscle cells were seen. Moreover, angular, homogeneous myofibers were observed close to each other. These muscles were more developed compared with the control group. In the muscles from the nano-Au+HS group, homogenous and closely located (packed) muscle cells were seen. Within cells, myofilaments were clearly seen and numerous mitochondria and a large number of satellite cells were also observed.

From the morphometric measurements, the number of satellite cells and muscle cells were determined (Table 4). HS and nano-Au+HS increased the number of muscle cells and satellite cells, compared to the control and nano-Au groups.
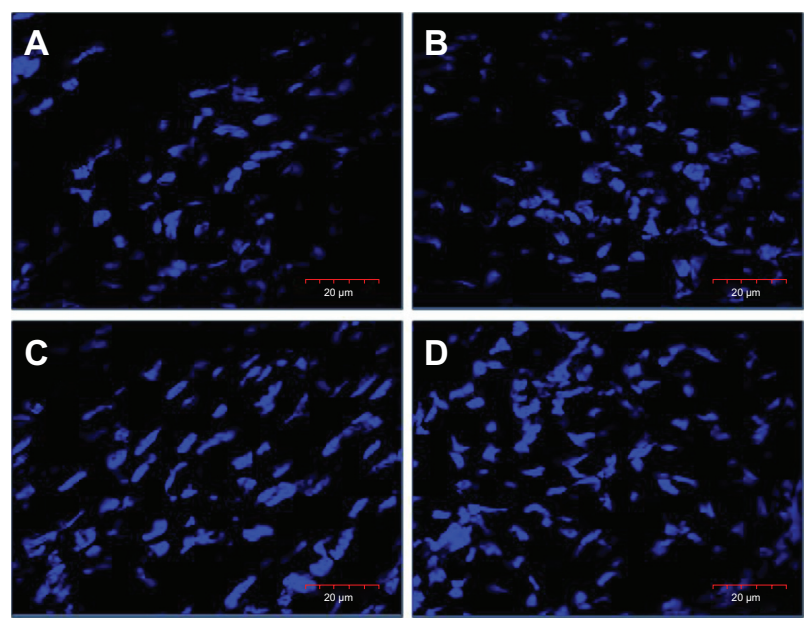

Figure 2 Images of nuclei (blue), stained with 4',6-diamidino-2-phenylindole, in the cross-section of the breast muscle of a chicken embryo on day 20 of incubation visualized using a confocal microscope. (A) Control, (B) gold nanoparticles, (C) heparan sulfate, and (D) gold nanoparticles and heparan sulfate complex.
To confirm the effects on the number of satellite cells, muscle samples were stained for $\mathrm{Pax}-7$ protein and observed with a confocal microscope (Figure 5). The muscles from embryos treated with $\mathrm{HS}$ and nano-Au+HS had a larger number of clusters of Pax-7 protein than the muscles from the nano-Au and control groups.

To confirm the results on the molecular level, gene expression of Pax-7 and FGF-2 in the breast muscle was measured (Table 5). At the mRNA level, HS significantly increased expression of $\mathrm{Pax}-7$ and significantly reduced the expression of $F G F-2$. However, there was no effect of nano-Au and no interaction between nano-Au and HS.

\section{Discussion}

In the present study, the chicken embryo was chosen as the animal model. It has a rapid rate of growth and its embryonic development is described in detail. ${ }^{21}$ The embryo is independent from the mother, ${ }^{22}$ it is highly sensitive to harmful factors, ${ }^{23}$ and it has been used as a suitable model for cancer therapy research, ${ }^{24}$ the determination of bacterial invasiveness, ${ }^{25}$ and new drug delivery systems development. ${ }^{26}$

Analysis of the present results led to the conclusion that administration of nano-Au, HS, and nano-Au+HS did not negatively affect the growth and development of chicken embryos. The results from other investigations suggest that, up to a certain concentration, nano-Au are not harmful to an organism, but with increasing concentrations they may have harmful effects. ${ }^{16-18,27,28}$ The present study was not undertaken to evaluate potential toxicity of nano-Au, however, it confirmed the lack of harmful effects of nano-Au administered in small quantities (concentration: $50 \mathrm{mg} / \mathrm{L}$, dose: $500 \mu \mathrm{L}$ ). Nano-Au did not negatively affect development of embryos 
Table 4 Morphometry of the breast muscle of chicken embryos without (-) or with gold nanoparticles and heparan sulfate

\begin{tabular}{|c|c|c|c|c|c|c|c|c|c|}
\hline & \multicolumn{4}{|c|}{ Treatment } & \multicolumn{5}{|c|}{ ANOVA } \\
\hline & \multicolumn{2}{|c|}{ Without HS } & \multicolumn{2}{|c|}{ With HS } & \multicolumn{4}{|l|}{ Effect } & \multirow{3}{*}{$\frac{\text { Interaction }}{P}$} \\
\hline & \multirow[t]{2}{*}{-} & \multirow[t]{2}{*}{ Nano-Au } & \multirow[t]{2}{*}{-} & \multirow[t]{2}{*}{ Nano-Au } & \multicolumn{2}{|c|}{ Nano-Au } & \multicolumn{2}{|l|}{ HS } & \\
\hline & & & & & $P$ & SEM & $P$ & SEM & \\
\hline Number of myocytes/ I0,000 $\mu \mathrm{m}^{2 *}$ & 23.0 & 27.5 & 18.5 & 32.1 & 0.197 & 3.21 & 0.0000 & 2.88 & 0.024 \\
\hline Number of satellite cells $/ \mathrm{I} 0,000 \mu \mathrm{m}^{2 *}$ & 7.1 & 8.4 & 6.8 & 8.7 & 0.213 & 0.91 & 0.0330 & 0.72 & 0.452 \\
\hline Fiber area $\left(\mu \mathrm{m}^{2}\right)^{*}$ & 19.9 & 25.0 & 19.2 & 21.4 & 0.002 & 1.06 & 0.0007 & 1.30 & 0.023 \\
\hline Number of nuclei/ $/ 0,000 \mu \mathrm{m}^{2 * *}$ & 16.1 & 19.7 & 15.7 & 21.4 & 0.004 & 0.84 & 0.0009 & 1.03 & 0.0009 \\
\hline
\end{tabular}

Notes: *Transmission electron microscope; **confocal microscope.

Abbreviations: ANOVA, analysis of variance; HS, heparan sulfate; nano-Au, gold nanoparticles; SEM, standard error of the mean.

(mortality, organ weight, and homeostasis). Nevertheless, the present results are from a short term study over 20 days of embryogenesis; because nano-Au can penetrate most tissues, ${ }^{29-31}$ their potentially negative effects may take place later in life.

In comparison to $\mathrm{Au}, \mathrm{HS}$ is a natural component of tissues and given at the concentration of $0.032 \mathrm{mg} / \mathrm{L}$ and the dose of $500 \mu \mathrm{L}$ had no adverse effects on embryonic development; moreover, HS reduced the mortality of embryos and decreased the heart weight compared to the other groups. The heart develops from cardiomyocyte precursors and even at the beginning of embryogenesis works together with the developing outer network of blood vessels. ${ }^{22}$ According to Ausprunk, ${ }^{32} \mathrm{HS}$ is involved in the differentiation and development of arterial and venous vessels of the chorioallantoic membrane. A key factor for vascular development is vascular endothelial growth factor. ${ }^{33}$ HS can partially activate an inactive form of vascular endothelial growth factor, prolonging its biological activity. ${ }^{34}$ Furthermore, addition
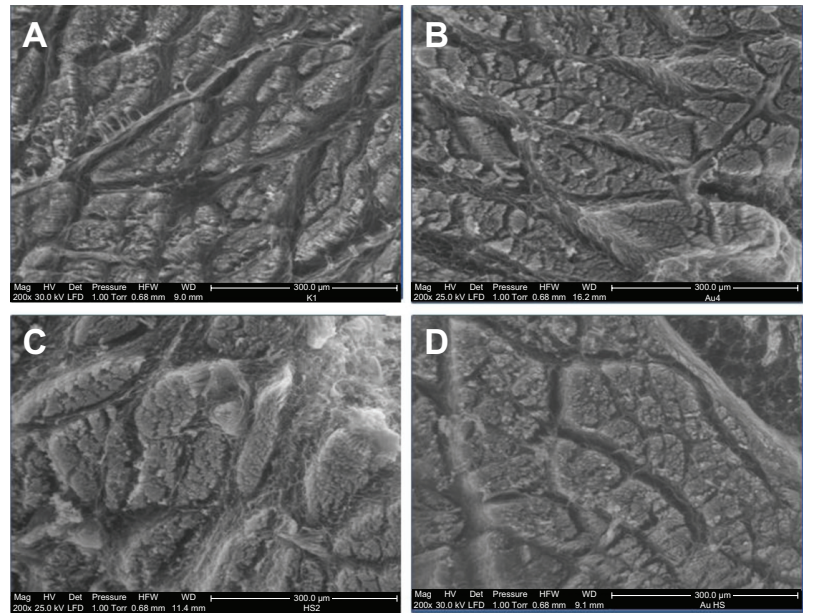

Figure 3 Images of the ultrastructure of the cross-section of the breast muscle of a chicken embryo on day 20 of incubation visualized using scanning electron microscopy (environmental scanning electron microscope mode).(A) Control,(B) gold nanoparticles, (C) heparan sulfate, and (D) gold nanoparticles and heparan sulfate complex. of a sulfated oligosaccharide enhances angiogenesis and stabilizes the capillary network of new blood vessels. ${ }^{10,35}$ Thus, a properly developed system of blood vessels of the correct diameter may decrease the resistance of peripheral vessels and, consequently, slightly decrease the force of heart contractions, leading to a proper heart weight. It should also be noted that the activity of alanine aminotransferase, aspartate aminotransferase, and other biochemical parameters of blood did not change, which otherwise could be the sign of distortion in the homeostasis of the organism, including the circulatory system.

Assessing the dynamics of muscle development, it was found that the total number of DAPI-labeled nuclei increased after in ovo HS injection, indicating enhanced dynamics of embryonic muscle development. Within the muscle tissue of the developing chicken embryo, nuclei of various cells can be observed: multinuclear muscle cells, connective tissue cells, blood cells, nerve cells, satellite cells, and other stem cells, but the muscle cells and muscle stem cells are dominant. ${ }^{2}$
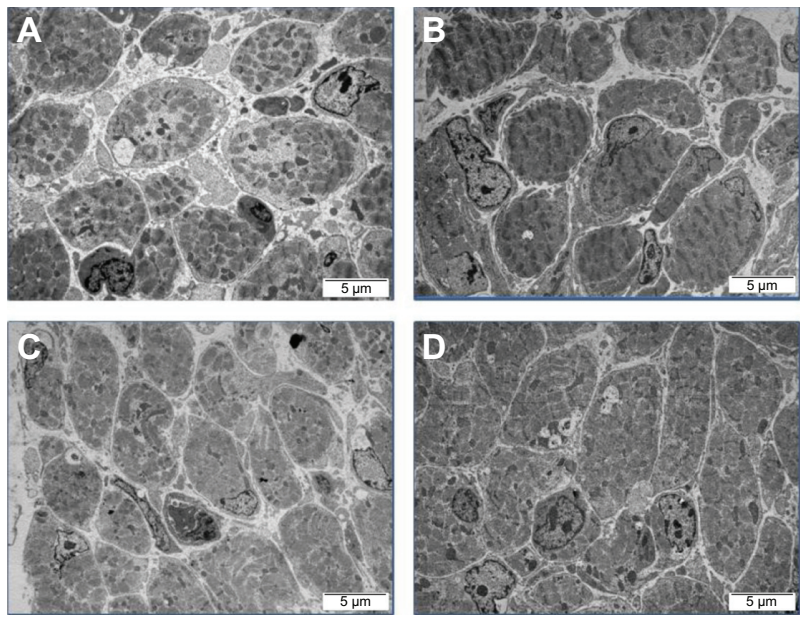

Figure 4 Images of the ultrastructure of the cross-section of the breast muscle of a chicken embryo on day 20 of incubation visualized using transmission electron microscopy. (A) Control, (B) gold nanoparticles, (C) heparan sulfate, and (D) gold nanoparticles and heparan sulfate complex. 

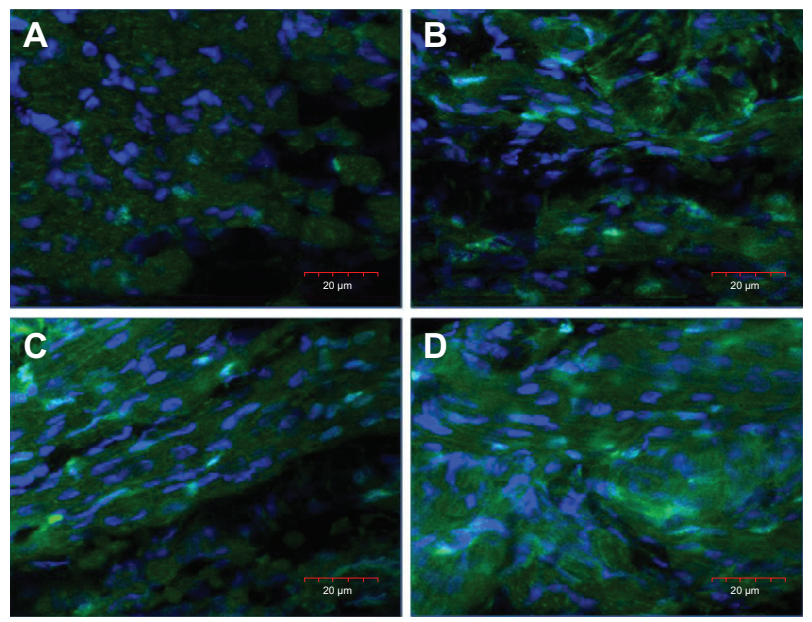

Figure 5 Images of Pax-7 positive nuclei, shown as an overlaid image of 4',6diamidino-2-phenylindole-stained nuclei (blue) and Pax-7 nuclei stained with fluorescein isothiocyanate (green), in the cross-section of the breast muscle of a chicken embryo on day 20 of incubation visualized using a confocal microscope. (A) Control, (B) gold nanoparticles, (C) heparan sulfate, and (D) gold nanoparticles and heparan sulfate complex.

The analysis of images obtained from SEM and TEM clearly showed an increase in the number of muscle cells after treatment with HS. To explain this phenomenon, two mechanisms could be considered; the first may indicate a scarcity of HS, which is essential for muscle development while the second may point to the stimulating effects of HS. In the present experiment, morphological defects seen in the control group may confirm the first mechanism that the quantity of HS or it precursors in the egg was not sufficient for optimal muscle development.

The mechanism of formation of muscle structures, depending on the chemical composition of the extracellular matrix, is not fully known. Myogenesis starts early in embryonic development and $F G F-2$ plays a key role in mesoderm induction. ${ }^{36}$ This factor stimulates proliferation and inhibits cell differentiation ${ }^{37}$ by suppressing the transcription of myogenin. ${ }^{38} \mathrm{HS}$ allows cells to bind $F G F-2$ and with an increasing number of sulfur groups, the binding efficiency increases, ${ }^{39,40}$ while a loss of sulfur groups blocks glycosaminoglycan activity. ${ }^{41}$
Inhibition of proliferation because of HS deficiency and premature cell differentiation is likely to reduce the number of cells in the final stages of embryonic development and ultimately may lead to defective tissue structure, especially in intensively growing organisms..$^{42,43}$

In the present experiment, expression of $F G F-2$ at the mRNA level in the HS groups decreased more than fourfold compared to the control group. The evaluation of morphological and molecular indices of muscle development was carried out at day 20 of incubation, hence at the end of embryogenesis, just before hatching. On day 20 of embryonic development, the process of muscle development is almost finished and the number of muscle cells is almost stable. This was manifested by the reduced expression of FGF-2 at mRNA level in HS muscles, indicating that the process of muscle fiber formation was completed. At the protein level, the concentration of $F G F-2$ protein was not significantly affected by HS, probably because protein expression occurs as a consequence of gene expression and is associated with a delay.

The effect of HS on $F G F-2$ expression at the mRNA level may be explained by an increased affinity of $F G F-2$ for its receptor, ${ }^{44} 46$ thereby enhancing the $F G F / F G F$ receptor interaction. It has also been demonstrated that both HS and heparin may increase the surface concentration of $F G F-2$, as well as assist in ligand dimerisation; ${ }^{46-48}$ consequently, signaling activities of $F G F-2$ might be more efficient in muscles enriched with HS. On the other hand, other mechanisms have also been suggested. The results from Wiedlocha et $\mathrm{a}^{49}$ indicate a receptor-independent mechanism for $F G F-1$ stimulation of proliferation. This may be true for $F G F-2$ as both growth factors bind to similar receptors. Therefore, signals important for cell proliferation can be initiated either via the FGF receptors or independent of them. Furthermore, Quarto and Amalric ${ }^{50}$ reported that $F G F-2$ stimulated plasminogen activator expression in L6 rat myoblasts devoid of functional FGF receptor. They suggested that the signal is transduced through HS proteoglycans. This may also explain

Table 5 Expression of PAX-7 and FGF-2 on the messenger ribonucleic acid level, normalized to ACTB, and on the protein level in the breast muscle of chicken embryos without (-) or with gold nanoparticles and heparan sulfate

\begin{tabular}{|c|c|c|c|c|c|c|c|c|c|}
\hline & \multicolumn{4}{|c|}{ Treatment } & \multicolumn{5}{|c|}{ ANOVA } \\
\hline & \multicolumn{2}{|c|}{ Without HS } & \multicolumn{2}{|l|}{ HS } & \multicolumn{4}{|c|}{ Effect } & \multirow{3}{*}{$\begin{array}{l}\text { Interaction } \\
P\end{array}$} \\
\hline & \multirow[t]{2}{*}{-} & \multirow[t]{2}{*}{ Nano-Au } & \multirow[t]{2}{*}{-} & \multirow[t]{2}{*}{ Nano-Au } & \multicolumn{2}{|c|}{ Nano-Au } & \multicolumn{2}{|l|}{ HS } & \\
\hline & & & & & $P$ & $\overline{\text { SEM }}$ & $P$ & $\overline{\text { SEM }}$ & \\
\hline PAX-7* & 0.80 & 0.98 & 0.57 & 1.21 & 0.435 & 0.156 & 0.0086 & 0.358 & 0.845 \\
\hline FGF-2* & 2.63 & 2.70 & 4.40 & 0.94 & 0.950 & 0.705 & 0.0024 & 0.117 & 0.806 \\
\hline FGF-2 pg/mg protein** & 132 & 127 & 144 & 118 & 0.716 & 8.4 & 0.217 & 10.3 & 0.119 \\
\hline
\end{tabular}

Notes: *Messenger ribonucleic acid level; **protein level.

Abbreviations: ANOVA, analysis of variance; HS, heparan sulfate; nano-Au, gold nanoparticles; SEM, standard error of the mean. 
the decreased mRNA expression of $F G F-2$ in HS-treated embryos, which could have been caused by increased efficiency of $F G F-2$ and thereby diminished the requirement for the synthesis of this molecule.

TEM image analysis showed an increased number of satellite cells in the muscles of embryos treated with HS. The regeneration of muscle fibers in the postnatal period is highly dependent on the number of satellite cells formed during embryogenesis. Furthermore, the number of muscle satellite cells decreases with age. In chickens, in the late phase of muscle growth, it declines to less than $5 \%$ of the total number of muscle fibers. ${ }^{51}$ Thus, an increased pool of these cells during embryogenesis may protect from muscle atrophy later in life. ${ }^{52}$

To elucidate the effect of HS on muscle development, a number of cells containing protein Pax-7 and its gene expression at the mRNA level were estimated. Pax-7 is localized in the nucleus of satellite cells and is a recognized marker of these cells. ${ }^{7}$ Treatments with HS contributed to the increased number of Pax-7 positive cells and expression of the gene. In the present experiment, expression of $F G F-2$ at the mRNA level, close to hatching, was decreased in the HS groups. This may be related to the Pax-3 and Pax-7 genes, which are indirectly involved in the down regulation of $F G F-2$ via a feedback mechanism. ${ }^{53}$ Taking into consideration the fact that HS affected both the number of satellite cells as well as muscle cells, this indicates that HS modified the whole sequence of events during the maturation of muscles, increasing the formation of muscle fibers, and increasing the formation and incorporation of satellite cells in the breast muscle at the end of embryogenesis.

Assessing the impact of nano-Au on muscle development, it was measured that nano-Au increased the number of nuclei and enlarged the areas of fibers in the breast muscle. However, there was no effect of nano-Au on the number of satellite cells or on the number of muscle cells. These results may indicate that nano-Au could boost the number of nuclei in a single muscle fiber and/or increase the number of other cells. Certainly, more research is needed to elucidate the mechanisms of muscle fiber enlargement.

The present results have shown that cell and/or tissue requirements for functional compounds like sulfur-containing molecules may be a critical point for proper maturation and functioning of muscle. Moreover, nano-Au did not influence the homeostasis of the embryo organism, suggesting that they might be used as carriers of drugs and other bioactive compounds. Although these results were obtained from chicken embryos, which develop quickly, they indicate the potential applicability of $\mathrm{HS}$, nano-Au, and complexes of these materials for nutritional and therapeutic procedures.

\section{Conclusion}

Nano-Au and HS, administered in ovo to chicken embryos on the first day of embryogenesis, did not adversely affect mortality, organ weight, and homeostasis of the embryos by day 20 of embryonic development. HS improved the development and maturation of breast muscle by increasing the number of myocytes, satellite cells, and nuclei, and by increasing area of muscle fibers. Furthermore, the nanoAu+HS complex contributed to the increased number of myocytes and nuclei, and enlarged area of muscle fibers. The results indicate that the administration of HS and nano-Au affects muscle development and that this effect is enhanced by conjugating HS with nano-Au.

\section{Acknowledgments}

This work was supported by grants: "New, multifunctional nanopowder of carbon" 357/ERA-NET 2008-2011 and Danish Agency for Science, Technology, and Innovation \#2106-08-0025.

\section{Disclosure}

The authors report no conflicts of interest in this work.

\section{References}

1. Zammit PS, Relaix F, Nagata Y, et al. Pax 7 and myogenic progression in skeletal muscle satellite cells. J Cell Sci. 2006;119(Pt 9):1824-1832.

2. Velleman SG. Muscle development in the embryo and hatchling. Poult Sci. 2007;86(5):1050-1054.

3. Morgan JE, Partridge TA. Muscle satellite cells. Int J Biochem Cell Biol. 2003;35(8):1151-1156.

4. Griffin HD, Goddard C. Rapidly growing broiler (meat-type) chickens. Their origin and use for comparative studies of the regulation of growth. Int J Biochem. 1994;26(1):19-28.

5. McKinnell IW, Ishibashi J, Le Grand F, et al. Pax7 activates myogenic genes by recruitment of a histone methyltransferase complex. Nat Cell Biol. 2008;10(1):77-84.

6. Seale P, Sabourin LA, Girgis-Gabardo A, Mansouri A, Gruss P, Rudnicki MA. Pax 7 is required for the specification of myogenic satellite cells. Cell. 2000;102(6):777-786.

7. Holterman CE, Rudnicki MA. Molecular regulation of satellite cell function. Semin Cell Dev Biol. 2005;16(4-5):575-584.

8. Miura T, Kishioka Y, Wakamatsu J, et al. Decorin binds myostatin and modulates its activity to muscle cells. Biochem Biophys Res Commun. 2006;340(2):675-680.

9. Tumova S, Woods A, Couchman JR. Heparan sulfate proteoglycans on the cell surface: versatile coordinators of cellular functions. Int $J$ Biochem Cell Biol. 2000;32(3):269-288.

10. Kemp MM, Kumar A, Mousa S, et al. Gold and silver nanoparticles conjugated with heparin derivative possess anti-angiogenesis properties. Nanotechnology. 2009:20(45):455104.

11. Lanone S, Boczkowski J. Biomedical applications and potential health risks of nanomaterials: molecular mechanisms. Curr Mol Med. 2006;6(6):651-663.

12. Ghosh P, Han G, De M, Kima CK, Rotello VM. Gold nanoparticles in delivery applications. Adv Drug Deliv Rev. 2008;60(11):1307-1315.

13. Mukherjee $P$, Bhattacharya R, Wang $P$, et al. Antiangiogenic properties of gold nanoparticles. Clin Cancer Res. 2005;11(9):3530-3534. 
14. Han G, Ghosh P, De M, Rotello VM. Drug and gene delivery using gold nanoparticles. Drug Deliv. 2007;3(1):40-45.

15. Murphy CJ, Gole AM, Stone JW, et al. Gold nanoparticles in biology: beyond toxicity to cellular imaging. Acc Chem Res. 2008;41(12): 1721-1730.

16. Connor EE, Mwamuka J, Gole A, Murphy CJ, Wyatt MD. Gold nanoparticles are taken up by human cells but do not cause acute cytotoxicity. Small. 2005;1(3):325-327.

17. Browning LM, Lee KJ, Huang T, Nallathamby PD, Lowman JE, Xu XH. Random walk of single gold nanoparticles in zebrafish embryos leading to stochastic toxic effects on embryonic development. Nanoscale. 2009;1(1):138-152.

18. Lasagna-Reeves C, Gonzalez-Romero D, Barria MA, et al. Bioaccumulation and toxicity of gold nanoparticles after repeated administration in mice. Biochem Biophys Res Commun. 2010;393(4):649-655.

19. Zhao SY, Wang S, Kimura K. The first example of ordered twodimensional self-assembly of Au nanoparticles from stable hydrosol. Langmuir. 2004;20(5):1977-1979.

20. Pyrpassopoulos S, Niarchos D, Nounesis G, Boukos N, Zafiropoulou I, Tzitzios V. Synthesis and self-organization of $\mathrm{Au}$ nanoparticles. Nanotechnology. 2007;18(48):485604.

21. Hamburger V, Hamilton HL. A series of normal stages in the development of the chick embryo. J Morphol. 1951;88(1):49-92.

22. Ribatti D. The Chick Embryo Chorioallantoic Membrane in the Study of Angiogenesis and Metastasis. New York: Springer Science+Business Media B.V; 2010

23. Heinz GH, Hoffman DJ, Klimstra JD, Stebbins KR, Kondrad SL, Erwin CA. Species differences in the sensitivity of avian embryos to methylmercury. Arch Environ Contam Toxicol. 2009;56(1):129-138.

24. Luyten GP, Mooy CM, De Jong PT, Hoogeveen AT, Luider TM. A chicken embryo model to study the growth of human uveal melanoma. Biochem Biophys Res Commun. 1993;192(1):22-29.

25. Gibbs PS, Petermann SR, Wooley RE. Comparison of several challenge models for studies in avian colibacillosis. Avian Dis. 2004;48(4): 751-758.

26. Vargas A, Zeisser-Labouèbe M, Lange N, Gurny R, Delie F. The chick embryo and its chorioallantoic membrane (CAM) for the in vivo evaluation of drug delivery systems. Adv Drug Deliv Rev. 2007;59(11):1162-1176.

27. Pernodet N, Fang X, Sun Y, et al. Adverse effects of citrate/gold nanoparticles on human dermal fibroblasts. Small. 2006;2(6):766-773.

28. Bar-Ilan O, Albrecht RM, Fako VE, Furgeson DY. Toxicity assessments of multisized gold and silver nanoparticles in zebrafish embryos. Small. 2009;5(16):1897-1910.

29. De Jong WH, Hagens WI, Krystek P, Burger MC, Sips AJ, Geertsma RE. Particle size-dependent organ distribution of gold nanoparticles after intravenous administration. Biomaterials. 2008;29(12): 1912-1919.

30. Sonavane G, Tomoda K, Makino K. Biodistribution of colloidal gold nanoparticles after intravenous administration: effect of particle size. Colloids Surf B Biointerfaces. 2008;66(2):274-280.

31. Lu S, Xia D, Huang G, Jing H, Wang Y, Gu H. Concentration effect of gold nanoparticles on proliferation of keratinocytes. Colloids Surf B Biointerfaces. 2010;81(2):406-411.

32. Ausprunk DH. Distribution of hyaluronic acid and sulfated glycosaminoglycans during blood-vessel development in the chick chorioallantoic membrane. Am J Anat. 1986;177(3):313-331.

International Journal of Nanomedicine

\section{Publish your work in this journal}

The International Journal of Nanomedicine is an international, peerreviewed journal focusing on the application of nanotechnology in diagnostics, therapeutics, and drug delivery systems throughout the biomedical field. This journal is indexed on PubMed Central, MedLine, CAS, SciSearch ${ }^{\circledR}$, Current Contents ${ }^{\circledR} /$ Clinical Medicine,
33. Yancopoulos GD, Davis S, Gale NW, Rudge JS, Wiegand SJ, Holash J. Vascular-specific growth factors and blood vessels formation. Nature. 2000;407(6801):242-248

34. Robinson CJ, Stringer SE. The splice variants of vascular endothelial growth factor (VEGF) and their receptors. $J$ Cell Sci. 2001;114(Pt 5): 853-865.

35. Mousa SA, Feng X, Xie J, et al. Synthetic oligosaccharide stimulates and stabilizes angiogenesis: structure-function relationships and potential mechanisms. Cardiovasc Pharmacol. 2006;48(2):6-13.

36. Isaacs HV, Tannahill D, Slack JM. Expression of a novel FGF in the Xenopus embryo. A new candidate inducing factor for mesoderm formation and anterioposterior specification. Development. 1992;114(3):711-720.

37. Allen RE, Goll DE. Cellular and developmental biology of skeletal muscle as related to muscle growth. In: Scanes C, editor. Biology of Growth of Domestic Animals. Ames, IA: Iowa State Press; 2003:148-169.

38. Brunetti A, Goldfine ID. Role of myogenin in myoblast differentiation and its regulation by fibroblast growth factor. $J$ Biol Chem. 1990;265(11):5960-5963

39. Bernfield M, Götte M, Park PW, et al. Functions of cell surface heparan sulfate proteoglycans. Annu Rev Biochem. 1999;68:729-777.

40. Kjellen L, Lindahl U. Proteoglycans: structures and interactions. Annu Rev Biochem. 1991;60:443-475.

41. Casu B, Guerrini M, Guglieri S, et al. Undersulfated and glycolsplit heparins endowed with antiangiogenic activity. $J$ Med Chem. 2004;47(4):838-848.

42. Birchmeier C, Gherardi E. Developmental roles of HGF/SF and its receptor, the c-Met tyrosine kinase. Trends Cell Biol. 1998;8(10):404-410.

43. Cool SM, Nurcombe V. Heparan sulfate regulation of progenitor cell fate. J Cell Biochem. 2006;99(4):1040-1051.

44. Pantoliano MW, Horlick RA, Springer BA, et al. Multivalent ligandreceptor binding interactions in the fibroblast growth factor system produce a cooperative growth factor and heparin mechanism for receptor dimerization. Biochemistry. 1994;33(34):10229-10248.

45. Roghani M, Mansukhani A, Dell'Era P, et al. Heparin increases the affinity of basic fibroblast growth factor for its receptor but is not required for binding. J Biol Chem. 1994;269(6):3976-3984.

46. Pellegrini L. Role of heparan sulfate in fibroblast growth factor signaling: a structural view. Curr Opin Struct Biol. 2001;11(5):629-634.

47. Ornitz DM. FGFs, heparan sulfate and FGFRs: complex interactions essential for development. Bioessays. 2000;22(2):108-112.

48. Schlessinger J, Plotnikov N, Ibrahimi OA, et al. Crystal structure of a ternary FGF-FGFR-heparin complex reveals a dual role for heparin in FGFR binding dimerization. Mol Cell. 2000;6(3):743-750.

49. Wiedlocha A, Falnes PO, Madshus IH, Sandvig K, Olsnes S. Dual mode of signal transduction by externally added acidic fibroblast growth factor. Cell. 1994;76(6):1039-1051.

50. Quarto N, Amalric F. Heparan sulfate proteoglycans are transducers of FGF-2 signaling. J Cell Sci. 1994;107(Pt 11):3201-3212.

51. Hawke TJ, Garry DJ. Myogenic satellite cells: physiology to molecular biology. J Appl Physiol. 2001;91(2):534-551.

52. Zhang L, Wang XH, Wang H, Du J, Mitch WE. Satellite cell dysfunction and impaired IGF-1 signaling cause CKD-induced muscle atrophy. J Am Soc Nephrol. 2010;21(3):419-427.

53. Lagha M, Sato T, Bajard L, et al. Regulation of skeletal muscle stem cell behavior by Pax3 and Pax7. Cold Spring Harb Symp Quant Biol. 2008;73:307-315

Journal Citation Reports/Science Edition, EMBase, Scopus and the Elsevier Bibliographic databases. The manuscript management system is completely online and includes a very quick and fair peer-review system, which is all easy to use. Visit http://www.dovepress.com/ testimonials.php to read real quotes from published authors. 